\title{
When Politics and Particles Collide
}

\author{
For particle physicist Yangyang Cheng, politics and science are clearly \\ intertwined; it's political ideals that make open scientific collaboration \\ possible.
}

\section{By Sophia Chen}

\begin{abstract}
$\Lambda$ s a physicist, Yangyang Cheng searches for hypothesized dark matter particles in CERN's Large Hadron Collider data and develops next-generation hardware for the facility's Compact Muon Solenoid (CMS) detector. Outside of physics, the Cornell University postdoc, who lives in Chicago, writes prolifically about the sticky intersection of science and politics through current events and personal experiences, in publications ranging from The New York Times to Teen Vogue, and also in a monthly column on SupChina.
\end{abstract}

A Chinese native (Cheng moved to the US in 2009 for graduate school), she unabashedly tackles controversial topics in her writing. In thoughtful, earnest essays, she discusses the flawed scientific systems that enable harmful technology, the exploitation of science for nationalist propaganda in China, and

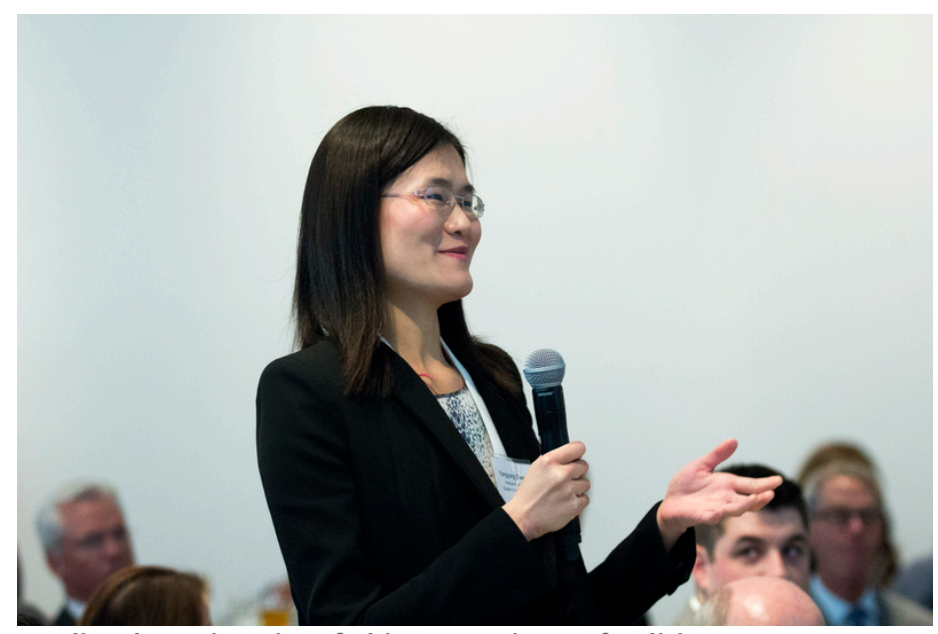

Credit: The University of Chicago Institute of Politics the emotional realities of living as an immigrant scientist in the US. Cheng spoke with Physics about her varied professional life.

\section{You do so many things. What made you decide to become a physicist?}

If I had grown up in a free country, I would not have become a scientist. When I was little, I was interested in both the mysteries of nature and the affairs of people. But I couldn't become a journalist without freedom of the press, and I couldn't become a lawyer without the rule of law. A career in fundamental science was one option that I felt I could pursue without compromise.

Particle physics fascinates me for two reasons: First, I find thinking about fundamental questions of the Universe emotionally sustaining. Second, I am captured by the idea of thousands of people from all over the world working together on a common goal that isn't for national defense or material gain.

In addition to research, you are also politically active. How did you get started?

I've long been intrigued by the American electoral process, so when I moved to Chicago, I searched for opportunities to experience democracy in action. As a foreign student, I couldn't vote, but I could volunteer my time. In 2012, I volunteered for a phone bank for President Obama's re-election campaign. In 2013, I became involved with the Institute of Politics at the University of Chicago, where I helped launch their International Policy Program-a student-run program that hosts discussions on international affairs and offers mentorship for students who 
aspire to careers in that area. I also travel regularly to Washington D.C. to meet Congressional staff to advocate for basic research funding.

\section{In 2017, you reported on the prospects of a} next-generation Chinese collider, for a story in Foreign Policy. The article discusses whether an authoritarian nation can properly host such a facility, which requires open international collaboration. You wrote that an official at the Chinese Academy of Sciences whom you interviewed became hostile, accusing you of trying to kill the project. Can you describe that experience?

During the interview for the story, I asked matter-of-fact questions. I asked whether there would be a branch of the Chinese Communist Party at the proposed collider because that would speak to the political control the government intended to have over the facility. I asked a yes-or-no question, so that he wouldn't have to give his opinions. I thought he might decline to comment, but instead he threatened me. He had a very authoritarian mindset: kill the story if you don't like the questions.

I did the interview by phone from a hotel room in DC, when I was on one of my many science advocacy trips. One day I was being threatened by a fellow scientist, and the next I was on Capitol Hill talking openly with elected officials. The contrast was wild.

As the interview was actually on-the-record, I decided to shield the official's name out of empathy for his position within an authoritarian system. It is not my intention to admonish any individual.

\section{When did you realize that science was a political activity?}

It's always been obvious to me. Any human endeavor is political-especially science, which is funded through government activity. When scientists claim they are apolitical, I think that is just self-deception.

Following the Jeffrey Epstein scandal [in 2019], I reflected on the ethical responsibility of scientists in relation to funding. At the time, the Massachusetts Institute of Technology was collaborating with a Chinese tech company, iFlyTek, which supplies the Chinese government with surveillance technology, especially in the northwestern region of Xinjiang, where over one million Muslim minorities have been held at "political re-education" camps. This company spun out of my alma mater, so it made me think about my complicity in terms of my institutional affiliations. We are all part of an unjust system.

\section{What does it mean to you to be a physicist?}

Being a physicist is an integral part of my identity.

I view being a physicist as analogous to being a professional athlete. Athletes dedicate their time to training and competing, but only for a short time: no athlete competes in the Olympics for their entire life. Similarly, I'm dedicated to physics, and I want to make the most of my time as a researcher. But I don't see the career as necessarily a lifelong one.

Being a physicist, like being an athlete, shapes my mind and how I move through the world. That will continue even if I leave research: once a physicist, always a physicist.

Know a physicist with a knack for explaining their research to others? Write to physics@aps.org. All interviews are edited for brevity and clarity.

Sophia Chen is a freelance science writer based in Columbus, Ohio. 